\title{
Comprehensive analysis of spread through air spaces in lung adenocarcinoma and squamous cell carcinoma using the 8th edition AJCC/UICC staging system
}

Meng Jia, Shili Yu, Jiaqi Yu, Yuemin Li, Hongwen Gao and Ping-Li Sun º

\begin{abstract}
Background: This study aimed to comprehensively investigate the effect of spread through air spaces (STAS) on clinicopathologic features, molecular characteristics, immunohistochemical expression, and prognosis in lung adenocarcinomas (ADC) and squamous cell carcinomas (SQCC) based on the 8th edition AJCC/UICC staging system.
\end{abstract}

Methods: In total, 303 ADC and 121 SQCC cases were assessed retrospectively. Immunohistochemical staining was performed for E-cadherin, vimentin, Ki67, survivin, BCl-2, and Bim. Correlations between STAS and other parameters were analyzed statistically.

Results: STAS was observed in 183 (60.4\%) ADC and 39 (32.2\%) SQCC cases. In ADC, the presence of STAS was associated with wild-type EGFR, ALK and ROS1 rearrangements, low E-cadherin expression, and high vimentin and Ki67 expression. In SQCC, STAS was associated with low E-cadherin expression and high vimentin and survivin expression. Based on univariate analysis, STAS was associated with significantly shorter disease-free survival (DFS) and overall survival (OS) in ADC. In SQCC, STAS tended to be associated with shorter OS. By multivariate analysis, STAS was an independent poor prognostic factor in ADC for DFS but not OS. Stratified analysis showed that STAS was correlated with shorter DFS for stage I, II, IA, IB, and IIA ADC based on univariate analysis and was an independent risk factor for DFS in stage I ADC cases based on multivariate analysis.

Conclusions: Our findings revealed that STAS is an independent negative prognostic factor for stage I ADC using the new 8th edition AJCC/UICC staging system. Stage I patients with STAS should be followed up more closely and might need different treatment strategies.

Keywords: Non-small cell lung cancer, Adenocarcinoma, Squamous cell carcinoma, Spread through air spaces (STAS), 8th edition AJCC/UICC staging system

\footnotetext{
* Correspondence: pinglisun@naver.com

Department of pathology, The Second Hospital of Jilin University, 218

Ziqiang Road, Changchun 130041, Jilin, China
}

(c) The Author(s). 2020 Open Access This article is licensed under a Creative Commons Attribution 4.0 International License, which permits use, sharing, adaptation, distribution and reproduction in any medium or format, as long as you give appropriate credit to the original author(s) and the source, provide a link to the Creative Commons licence, and indicate if changes were made. The images or other third party material in this article are included in the article's Creative Commons licence, unless indicated otherwise in a credit line to the material. If material is not included in the article's Creative Commons licence and your intended use is not permitted by statutory regulation or exceeds the permitted use, you will need to obtain permission directly from the copyright holder. To view a copy of this licence, visit http://creativecommons.org/licenses/by/4.0/. The Creative Commons Public Domain Dedication waiver (http://creativecommons.org/publicdomain/zero/1.0/) applies to the data made available in this article, unless otherwise stated in a credit line to the data. 


\section{Background}

Spread through air spaces (STAS) is a phenomenon of lung cancer spread, which is defined as tumor cells within air spaces in the lung parenchyma beyond the edge of the main tumor. STAS was first named by Kadota and colleagues in 2015 [1] and has received widespread attention since its identification. The significance of STAS is predominantly due to its predictive value on prognosis. The presence of STAS was found to be correlated with aggressive clinicopathologic features and poor prognosis in several histological types of lung cancers. Moreover, according to 2015 World Health Organization (WHO) classification [2], this morphological manifestation was listed as an exclusion criterion for the diagnosis of adenocarcinoma in situ and minimally invasive adenocarcinoma (MIA). Although the clinicopathologic features and prognostic significance of STAS have been investigated, the published studies were mainly conducted according to the 7 th edition of American Joint Committee on Cancer (AJCC)/Union for International Cancer Control (UICC) staging system; few studies have analyzed the association between STAS and pathological stage (p-stage) using the new 8th edition AJCC/UICC staging system. Compared with the 7th edition of AJCC/UICC staging system, the change in the new TNM staging criteria mainly concerns the description of T. T stage is subdivided at a $1-\mathrm{cm}$ cut-off when the tumor size is less than or equal to $5 \mathrm{~cm} \mathrm{[3],} \mathrm{and} \mathrm{this}$ improved $\mathrm{T}$ staging results in a better correlation with prognosis. However, although STAS has been reported to be significant with respect to the prediction of survival for early-stage tumors, few studies have analyzed the significance of STAS based on a single subdivided stage exclusively.

In addition to the aforementioned challenges, the association between STAS and molecular characteristics of lung adenocarcinoma (ADC) has not been clearly explicated, and this issue has been barely studied in Chinese patients. Meanwhile, little progress has been achieved in elucidating the association between STAS and the immunohistochemical expression of epithelial-mesenchymal transition (EMT), proliferation, and apoptosisrelated markers. The purpose of this study was to comprehensively investigate the effect of STAS on clinicopathologic features, molecular characteristics, immunohistochemical expression, and prognosis in lung ADC and squamous cell carcinomas (SQCCs) based on the 8th edition AJCC/UICC staging system.

\section{Methods}

This study was approved by the ethics committee of The Second Hospital of Jilin University (Changchun, China). Written informed consent was also obtained from all patients.

\section{Patients and sample collection}

We retrospectively collected the data and tissue specimens of patients who underwent surgical resection (limited resection or lobectomy) for primary lung ADCs and SQCCs between 2010 and 2014. In our institution, limited resection (including wedge resection and segmentectomy) was performed based on a comprehensive consideration of the following issues: (1) tumors smaller than $3 \mathrm{~cm}$ with radiologically ground glass node (consolidation/tumor ratio $<0.5$ ); (2) tumor location within the outer third of the lung parenchyma; (3) general status and respiratory function of the patients. Cases with neoadjuvant therapy, positive surgical margins, a diagnosis of multiple primary lung cancers, a diagnosis of in situ or MIA, and no available tumor slides for review were excluded from this study. In total, 303 cases of ADCs and 121 cases of SQCCs were assessed. Clinical parameters including patient age, sex, smoking history, tumor size, p-stage, and follow-up were collected from the original medical records. The tumor $\mathrm{p}$-stage was restaged using the 8th edition AJCC/UICC staging system. The period of follow-up ranged from 1 to 65 months.

\section{Histological review}

All tissue specimens were reviewed retrospectively. Pathological parameters including pleural invasion, blood and lymphatic vessel invasion, perineural invasion, and necrosis were recorded. For ADCs, comprehensive histologic subtyping was also performed. ADCs were classified as lepidic, acinar, papillary, micropapillary, or solid subtypes according to the 2015 WHO classification [2].

Tumor STAS was defined according to the descriptions summarized by Kadota et al. [1]. In each case, at least four slides were observed to detect STAS. The presence of STAS was recorded as "present" or "absent," regardless of the subtypes of STAS cells. Artificial fragments and other mimics including a micropapillary pattern of invasion and intra-alveolar macrophages were strictly evaluated and excluded.

\section{Immunohistochemistry}

Immunohistochemical staining was performed automatically using PT Link Pre-Treatment system (DAKO, CA, USA) and Autostainer Link 48 system (DAKO, CA, USA). Endogenous peroxidases were quenched with $3 \%$ $\mathrm{H}_{2} \mathrm{O}_{2}$ for $10 \mathrm{~min}$. The sections were incubated with primary antibodies (Additional file 1) for $30 \mathrm{~min}$. The samples was then incubated with the secondary biotinylated antibody for $20 \mathrm{~min}$. The slides were stained using 3, 3'-diaminobenzidine and counterstained with hematoxylin. 


\section{Scoring of immunostained tissue sections}

The expression of markers was quantified based on the extent of staining (by percentage of positive tumor cells: $0-100 \%$; for E-cadherin, only tumor cells with complete membranous staining were counted) and the intensity of staining (graded on a scale of $0-3$ as follows: 0 , no staining; 1 , weak staining; 2 , moderate staining; and 3 , strong staining). A semi-quantitative score was obtained by multiplying the grades of intensity by the percentage of positively stained cells. The median value of all the scores was chosen as the cut-off value to divide patients into high and low expression categories [4]. All specimens were evaluated under light microscopy by two independent pathologists (M.J. and P.L.S.).

\section{Analysis of adenocarcinoma-associated mutations and rearrangement}

Samples were analyzed for epidermal growth factor receptor (EGFR) mutations within exons 18 to 21 and KRAS (Kirsten rat sarcoma viral oncogene homolog) mutations at codons 12 and 13 using an amplification refractory mutation system (Super-ARMS EGFR Mutation Detection Kit and KRAS Mutation Detection Kit, Amoy Diagnostics Co. Ltd., Xiamen, China). The presence of anaplastic lymphoma kinase $(A L K)$ and ROS1 (ROS proto-oncogene 1, receptor tyrosine kinase) translocation was evaluated by fluorescence in situ hybridization as described previously $[5,6]$.

\section{Statistical analysis}

Statistical analyses were performed using the software Statistical Package for Social Sciences, version 22.0, for Windows (SPSS, IL, USA). Chi-squared or Fisher's exact tests were used to determine if any associations were evident between STAS and clinicopathologic parameters and the expression of immunohistochemical markers. Survival curves were determined using the KaplanMeier method, and statistical differences in survival times were determined using the log-rank test. The Cox proportional hazards model was applied for multivariate survival analysis. A $p$ value $<0.05$ was considered statistically significant.

\section{Results}

Patient clinicopathologic characteristics and outcome

In the cohort of $303 \mathrm{ADC}$ cases, there were 150 male and 153 female patients, ranging in age from 23 to 83 years (median of 65 years). The predominant invasive pattern was acinar in 154 (50.8\%), papillary in 82 (27.1\%), lepidic in $45(14.8 \%)$, solid in six $(2.0 \%)$, and micropapillary in $16(5.3 \%)$ cases. P-stage was IA in 86, IB in 87 , IIA in 46, IIB in 11, IIIA in 48, IIIB in five, and IV in 20 cases. The follow-up period was from 1 to 65 months with a median of 30 months. Ninety-one patients showed recurrence, and 32 patients died of disease in the last follow-up.

In the cohort of 121 SQCC cases, patient age ranged from 31 to 85 years (median 69 years). Most patients
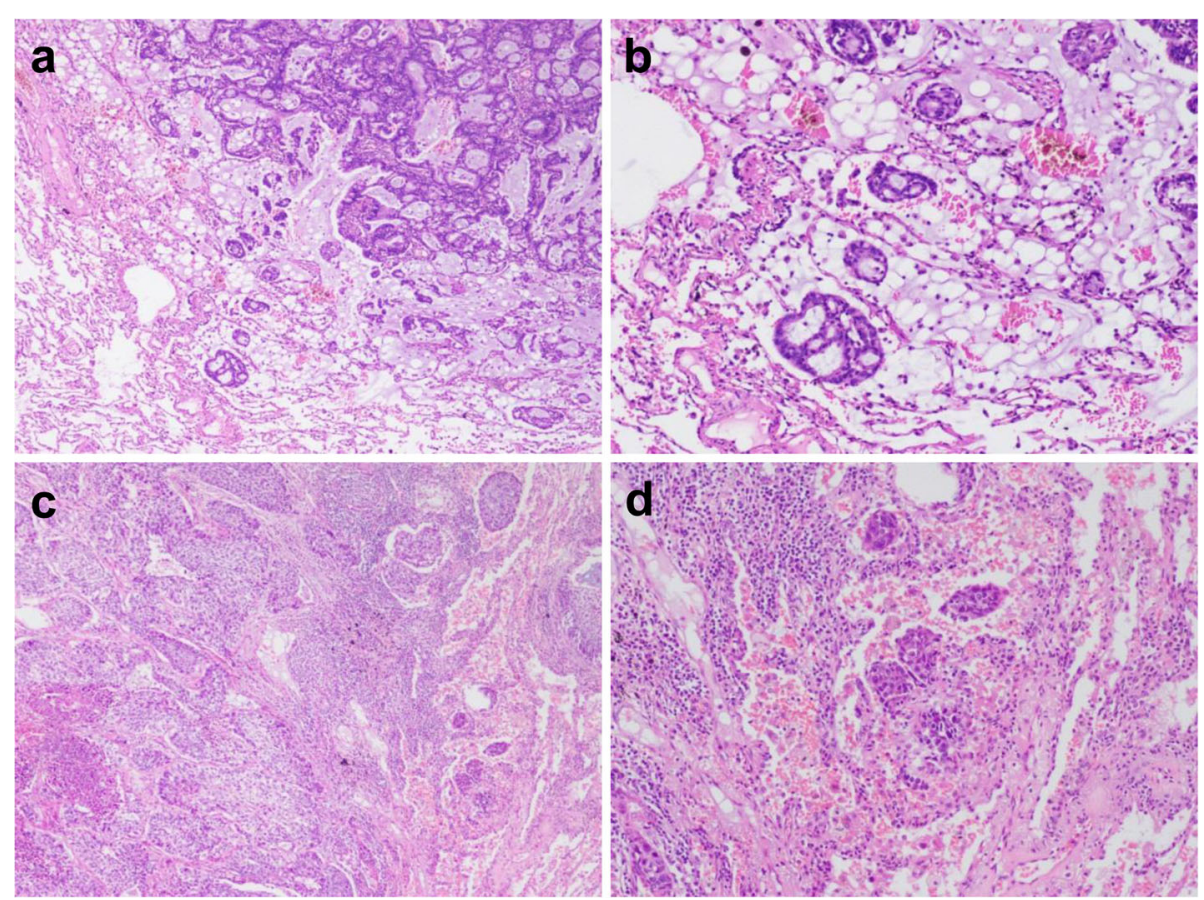

Fig. 1 Tumor spread through air spaces (STAS). a, b: STAS in lung adenocarcinoma (ADC); c, d: STAS in squamous cell carcinoma (SQCC). (a-d: H\&E staining; a, c: 40x; b, d: 100x) 
Table 1 Correlations between clinicopathological parameters and STAS in ADC

\begin{tabular}{|c|c|c|c|c|c|c|c|c|c|}
\hline \multirow[t]{2}{*}{ Parameters } & \multirow{2}{*}{$\begin{array}{l}\text { In } \\
\text { total }\end{array}$} & \multicolumn{2}{|l|}{ STAS } & \multirow[t]{2}{*}{$p$} & \multirow[t]{2}{*}{ Parameters } & \multirow{2}{*}{$\begin{array}{l}\text { In } \\
\text { total }\end{array}$} & \multicolumn{2}{|l|}{ STAS } & \multirow[t]{2}{*}{$p$} \\
\hline & & Positive(n(\%)) & Negative(n(\%)) & & & & Positive(n(\%)) & Negative(n(\%)) & \\
\hline In total & 303 & 183(60.4) & 120(39.6) & & StagelA & 86 & $39(21.3)$ & $47(39.2)$ & 0.111 \\
\hline \multicolumn{4}{|l|}{ Gender } & & StagelB & 87 & $50(27.3)$ & $37(30.8)$ & \\
\hline Female & 153 & $91(49.7)$ & $62(51.7)$ & 0.741 & StagellA & 46 & $29(15.8)$ & $17(14.2)$ & 0.146 \\
\hline Male & 150 & $92(50.3)$ & $58(48.3)$ & & StagellB & 11 & $10(5.5)$ & $1(0.8)$ & \\
\hline \multicolumn{5}{|l|}{ Age } & Stage III-IV & 73 & $55(30.1)$ & 18(15.0) & \\
\hline$\leq 65$ & 157 & $91(49.7)$ & $66(55.0)$ & 0.369 & \multicolumn{5}{|l|}{ EGFR mutation } \\
\hline$>65$ & 146 & $92(50.3)$ & $54(45.0)$ & & Negative & 143 & $96(52.5)$ & $47(39.2)$ & 0.023 \\
\hline \multicolumn{5}{|l|}{ Smoking history } & Positive & 160 & $87(47.5)$ & $73(60.8)$ & \\
\hline Non-smoker & 183 & $112(61.2)$ & $71(59.2)$ & 0.723 & \multicolumn{5}{|l|}{ KRAS mutation } \\
\hline Smoker & 120 & $71(38.8)$ & 49(40.8) & & Negative & 243 & 148(91.9) & 95(96.0) & 0.201 \\
\hline \multicolumn{5}{|l|}{ Tumor size } & Positive & 17 & $13(8.1)$ & $4(4.0)$ & \\
\hline$\leq 3 \mathrm{~cm}$ & 177 & 94(51.4) & $83(69.2)$ & 0.002 & \multicolumn{5}{|c|}{ ALK rearrangement } \\
\hline$>3 \mathrm{~cm}$ & 126 & $89(48.6)$ & $37(30.8)$ & & Negative & 279 & $160(87.4)$ & 119(99.2) & $<0.001$ \\
\hline \multicolumn{5}{|c|}{ Predominant subtype } & Positive & 24 & 23(12.6) & $1(0.8)$ & \\
\hline Acinar & 154 & 89(48.6) & $65(54.2)$ & 0.104 & \multicolumn{5}{|c|}{ ROS1 rearrangement } \\
\hline Papillary & 82 & $54(29.5)$ & $28(23.3)$ & & Negative & 294 & 174(95.1) & $120(100.0)$ & 0.013 \\
\hline Lepidic & 45 & $27(14.8)$ & 18(15.0) & & Positive & 9 & $9(4.9)$ & $0(0)$ & \\
\hline Solid & 6 & $1(0.5)$ & $5(4.2)$ & & . Oritelation & $\operatorname{tag}$ & and stage III-IV & & \\
\hline
\end{tabular}

Table 1 Correlations between clinicopathological parameters and STAS in ADC (Continued)
Presence of micropapillary

$\begin{array}{lllll}\text { Absent } & 229 & 115(62.8) & 114(95.0) & <0.001 \\ \text { Present } & 74 & 68(37.2) & 6(5.0) & \end{array}$

Pleural invasion

$\begin{array}{lllll}\text { Absent } & 168 & 93(50.8) & 75(62.5) & 0.045 \\ \text { Present } & 135 & 90(49.2) & 45(37.5) & \\ \text { Vascular invasion } & & & & \\ \text { Absent } & 189 & 92(50.3) & 97(80.8) & <0.001 \\ \text { Present } & 114 & 91(49.7) & 23(19.2) & \end{array}$

Lymphatic invasion

$\begin{array}{lllll}\text { Absent } & 148 & 58(31.7) & 90(75.0) & <0.001 \\ \text { Present } & 155 & 125(68.3) & 30(25.0) & \end{array}$

Perineural invasion

$\begin{array}{lllll}\text { Absent } & 280 & 163(89.1) & 117(97.5) & 0.007 \\ \text { Present } & 23 & 20(10.9) & 3(2.5) & \end{array}$

Tumor necrosis

$\begin{array}{lllll}\text { Absent } & 196 & 103(56.3) & 93(77.5) & <0.001 \\ \text { Present } & 107 & 80(43.7) & 27(22.5) & \\ \text { Tumor relapse } & & & & \\ \text { Absent } & 212 & 110(60.1) & 102(85.0) & <0.001 \\ \text { Present } & 91 & 73(39.9) & 18(15.0) & \end{array}$

Pathological stage

$$
\text { Stage I-II }
$$

were men $(n=119)$. P-stage was IA in 28, IB in 21 , IIA in 26 , IIB in 14 , IIIA in 28 , IIIB in one, and IV in three cases. The follow-up period was from 1 to 65 months with a median of 34 months. Thirty-two patients showed recurrence, and 16 patients died of disease in the last follow-up.

\section{Tumor STAS and its association with clinicopathologic parameters}

In the ADC cohort, tumor STAS was observed in 183 (60.4\%) cases (Fig. 1). The association between clinicopathologic parameters and STAS is summarized in Table 1. STAS was more frequently identified in tumors with pathological features characteristic of aggressive tumor behavior, such as larger tumor size $(p=0.002)$, presence of micropapillary pattern $(p<0.001)$, pleural invasion $(p=0.045)$, vascular invasion $(p<0.001)$, lymphatic invasion $(p<0.001)$, perineural invasion $(p=$ $0.007)$, presence of tumor necrosis $(p<0.001)$, and higher $\mathrm{p}$-stage $(p=0.003)$.

In the SQCC cohort, tumor STAS was observed in 39 (32.2\%) cases (Fig. 1). The association between clinicopathologic parameters and STAS is summarized in Table 2. STAS was significantly associated with the presence of lymphatic invasion $(p=0.020)$. STASpositive cases were more likely to show perineural invasion, although this trend was not statistically significant $(p=0.080)$. Other parameters including patient age, 
Table 2 Correlations between clinicopathological parameters and STAS in SQCC

\begin{tabular}{|c|c|c|c|c|}
\hline \multirow[t]{2}{*}{ Parameters } & \multirow{2}{*}{$\begin{array}{l}\text { In } \\
\text { total }\end{array}$} & \multicolumn{2}{|l|}{ STAS } & \multirow[t]{2}{*}{$p$} \\
\hline & & Positive(n(\%)) & Negative(n(\%)) & \\
\hline In total & 121 & $39(32.2)$ & $82(67.8)$ & \\
\hline \multicolumn{5}{|l|}{ Gender } \\
\hline Female & 2 & $0(0)$ & $2(2.4)$ & \multirow[t]{2}{*}{1.000} \\
\hline Male & 119 & $39(100.0)$ & $80(97.6)$ & \\
\hline \multicolumn{5}{|l|}{ Age } \\
\hline$\leq 65$ & 38 & 15(38.5) & $23(28.0)$ & \multirow[t]{2}{*}{0.249} \\
\hline$>65$ & 83 & $24(61.5)$ & $59(72.0)$ & \\
\hline \multicolumn{5}{|l|}{ Smoking history } \\
\hline Non-smoker & 6 & $0(0)$ & $6(7.3)$ & \multirow[t]{2}{*}{0.175} \\
\hline Smoker & 115 & $39(100.0)$ & $76(92.7)$ & \\
\hline \multicolumn{5}{|l|}{ Tumor size } \\
\hline$\leq 3 \mathrm{~cm}$ & 37 & 12(30.8) & $25(30.5)$ & \multirow[t]{2}{*}{0.975} \\
\hline$>3 \mathrm{~cm}$ & 84 & $27(69.2)$ & $57(69.5)$ & \\
\hline \multicolumn{5}{|l|}{ Pleural invasion } \\
\hline Absent & 82 & 28(71.8) & $54(65.9)$ & \multirow[t]{2}{*}{0.513} \\
\hline Present & 39 & $11(28.2)$ & $28(34.1)$ & \\
\hline \multicolumn{5}{|c|}{ Vascular invasion } \\
\hline Absent & 89 & $25(64.1)$ & $64(78.0)$ & \multirow[t]{2}{*}{0.104} \\
\hline Present & 32 & 14(35.9) & 18(22.0) & \\
\hline \multicolumn{5}{|c|}{ Lymphatic invasion } \\
\hline Absent & 68 & $16(41.0)$ & $52(63.4)$ & \multirow[t]{2}{*}{0.020} \\
\hline Present & 53 & $23(59.0)$ & $30(36.6)$ & \\
\hline \multicolumn{5}{|c|}{ Perineural invasion } \\
\hline Absent & 103 & $30(76.9)$ & $73(89.0)$ & \multirow[t]{2}{*}{0.080} \\
\hline Present & 18 & $9(23.1)$ & $9(11.0)$ & \\
\hline \multicolumn{5}{|l|}{ Tumor necrosis } \\
\hline Absent & 12 & $3(7.7)$ & $9(11.0)$ & \multirow[t]{2}{*}{0.750} \\
\hline Present & 109 & $36(92.3)$ & 73(89.0) & \\
\hline \multicolumn{5}{|l|}{ Tumor relapse } \\
\hline Absent & 89 & $29(74.4)$ & $60(73.2)$ & \multirow[t]{2}{*}{0.890} \\
\hline Present & 32 & 10(25.6) & $22(26.8)$ & \\
\hline \multicolumn{5}{|c|}{ Pathological stage } \\
\hline Stage I-II & 89 & $26(66.7)$ & 63(76.8) & $0.236^{*}$ \\
\hline StagelA & 28 & $8(20.5)$ & $20(24.4)$ & \multirow[t]{2}{*}{0.443} \\
\hline StagelB & 21 & $4(10.3)$ & 17(20.7) & \\
\hline StagellA & 26 & $11(28.2)$ & 15(18.3) & \multirow[t]{3}{*}{0.299} \\
\hline StagellB & 14 & $3(7.7)$ & $11(13.4)$ & \\
\hline Stage III-IV & 32 & 13(33.3) & 19(23.2) & \\
\hline
\end{tabular}

*Correlation between stage I-II and stage III-IV

smoking history, tumor size, pleural invasion, vascular invasion, tumor necrosis, and p-stage showed no differences between STAS-positive and STAS-negative cases.
Tumor STAS and molecular alterations in ADC

The association between STAS and molecular alterations was exclusively analyzed in the ADC cohort (Table 1 ). STAS-positive cases were more likely to harbor wildtype EGFR ( $p=0.023), A L K$ rearrangements $(p<0.001)$, or ROS1 rearrangements $(p=0.013)$. KRAS mutations were detected in 260 cases and no correlation was found between STAS and KRAS mutations $(p=0.201)$.

\section{Tumor STAS and immunohistochemical expression}

The association between STAS and immunohistochemical expression is summarized in Table 3. For both ADC and SQCC, the expression of E-cadherin and vimentin was significantly different between STAS-positive and STAS-negative cases. STAS-positive cases were more likely to show low E-cadherin expression $(p=0.001$ and 0.012 for ADC and SQCC, respectively) and high vimentin expression $(p=0.003$ and 0.034 for ADC and SQCC, respectively). In $\mathrm{ADC}, \mathrm{Ki} 67$ expression was higher in STAS-positive cases $(p<0.001)$, whereas this correlation was not observed in SQCC. The expression of survivin was significantly higher in STAS-positive SQCC $(p<$ 0.001) than in STAS-negative cases; however, this trend was not observed in ADC. The expression of Bcl-2 and Bim showed no correlation with the status of STAS in either ADC or SQCC.

\section{Survival analysis}

By univariate analysis, we first analyzed the association between conventional clinicopathologic factors and patient outcomes for ADC and SQCC separately. In ADC, patient age $>65$, tumor size $>3 \mathrm{~cm}$, the presence of pleural invasion, vascular invasion, lymphatic invasion, and more advanced $\mathrm{p}$-stage were associated with a significantly worse disease-free survival (DFS) and/or overall survival (OS) (Table 4). In SQCC, the presence of lymphatic invasion and more advanced p-stage was associated with a significantly worse DFS (Additional file 2).

Thereafter, we analyzed the prognostic significance of STAS. In ADC, STAS was associated with significantly shorter DFS (40.42 vs. 55.73 months; $p<0.001)$ and shorter OS (56.79 vs. 60.72 months; $p=0.025$; Fig. 2, Table 4). In SQCC, STAS was associated with shorter OS, although this trend was not statistically significant (48.90 vs. 59.67 months; $p=0.050$ ). STAS was not found to be associated with DFS in the SQCC cohort (44.95 vs. 48.72 months; $p=0.795$; Fig. 2, Additional file 2). Multivariate Cox analysis showed that STAS was an independent poor prognostic factor for ADC regarding DFS but not OS (DFS: hazard ratio (HR), 2.460; 95\% confidence interval (CI), 1.398-4.327; $p=0.002$; OS: HR, 1.187; 95\% CI, 0.466-3.026; $p=0.719$; Table 5). Given the lack of a statistically significant association between clinicopathologic parameters and survival in patients 
Table 3 Correlations between immunohistochemical expression and STAS

\begin{tabular}{|c|c|c|c|c|c|c|c|c|}
\hline \multirow[t]{2}{*}{ Antibodies } & \multirow{2}{*}{$\begin{array}{l}\text { In } \\
\text { total }\end{array}$} & \multicolumn{2}{|l|}{ STAS in ADC } & \multirow[t]{2}{*}{$p$} & \multirow{2}{*}{$\begin{array}{l}\text { In } \\
\text { total }\end{array}$} & \multicolumn{2}{|l|}{ STAS in SQCC } & \multirow[t]{2}{*}{$p$} \\
\hline & & Positive(n(\%)) & Negative(n(\%)) & & & Positive(n(\%)) & Negative(n(\%)) & \\
\hline \multicolumn{9}{|l|}{ E-cadherin } \\
\hline Low & 171 & 119(66.9) & $52(47.3)$ & 0.001 & 32 & $16(41.0)$ & $16(19.5)$ & 0.012 \\
\hline High & 117 & 59(33.1) & $58(52.7)$ & & 89 & 23(59.0) & $66(80.5)$ & \\
\hline \multicolumn{9}{|l|}{ Vimentin } \\
\hline Low & 143 & $76(42.7)$ & $67(60.9)$ & 0.003 & 54 & 12(30.8) & $42(51.2)$ & 0.034 \\
\hline High & 145 & $102(57.3)$ & 43(39.1) & & 67 & $27(69.2)$ & $40(48.8)$ & \\
\hline \multicolumn{9}{|l|}{ Survivin } \\
\hline Low & 113 & $67(37.6)$ & $46(41.8)$ & 0.481 & 77 & 15(38.5) & $62(75.6)$ & $<0.001$ \\
\hline High & 175 & $111(62.4)$ & $64(58.2)$ & & 44 & $24(61.5)$ & $20(24.4)$ & \\
\hline \multicolumn{9}{|l|}{ Ki67 } \\
\hline Low & 125 & $62(34.8)$ & $63(57.3)$ & $<0.001$ & 59 & $22(56.4)$ & $37(45.1)$ & 0.246 \\
\hline High & 163 & $116(65.2)$ & $47(42.7)$ & & 62 & 17(43.6) & $45(54.9)$ & \\
\hline \multicolumn{9}{|l|}{$\mathrm{BCl}-2$} \\
\hline Low & 115 & $76(42.7)$ & $39(35.5)$ & 0.223 & 71 & $22(56.4)$ & 49(59.8) & 0.727 \\
\hline High & 173 & 102(57.3) & $71(64.5)$ & & 50 & 17(43.6) & $33(40.2)$ & \\
\hline \multicolumn{9}{|l|}{ Bim } \\
\hline Low & 135 & 87(48.9) & 48(43.6) & 0.387 & 61 & 23(59.0) & $38(46.3)$ & 0.194 \\
\hline High & 153 & $91(51.1)$ & $62(56.4)$ & & 60 & $16(41.0)$ & $44(53.7)$ & \\
\hline
\end{tabular}

with SQCC, we did not subject the outcomes of patients in this group to multivariate analyses.

To investigate the significance of STAS in ADC of different stages, we analyzed the prognostic significance stratified by tumor stage. STAS was associated with shorter DFS and OS only in stage I-II tumors, but not in stages III-IV (DFS: $p<0.001$ vs. $p=0.736$; OS: $p=0.015$ vs. $p=0.332$; Table 4). Further stratification analysis showed that STAS was correlated with shorter DFS for stage I $(p<0.001)$, II $(p=0.007)$, IA $(p=0.009)$, IB $(p=$ $0.025)$, and IIA $(p=0.003)$ tumors based on univariate analysis (Fig. 3, Additional file 3). However, this observation was not observed with respect to OS. In multivariate analysis, STAS was an independent risk factor for DFS in stage I cases $(p=0.004$, Additional file 4). Multivariate analysis was not performed for stage II or IIA cases as STAS was the only risk factor for DFS. Stratification analysis was not performed for other stages of ADC or SQCC because of the small sample size in each stage.

\section{Discussion}

In this study, we investigated the association between STAS and clinicopathologic features, molecular alterations, the expression of immunohistochemical markers, and prognostic significance in both ADC and SQCC based on Chinese patients. We found that STAS was associated with aggressive clinicopathologic features, wild- type EGFR, rearranged $A L K$ or $R O S 1$, low expression of E-cadherin and high expression of vimentin, Ki67, and survivin. In the prognostic analysis, STAS was associated with poor DFS and OS in ADC by univariate analysis and was an independent risk factor for DFS by multivariate analysis. In addition, STAS was associated with poor DFS in single stage I, II, IA, IB, and IIA ADC patients according to the new 8th edition AJCC/UICC staging system.

Since 2018, a few studies have discussed the significance of STAS based on the 8th edition AJCC/UICC staging system, and the reported results mainly focused on ADC [7-15]. Some attention has been paid to the significance of STAS in stage I patients; however, few studies analyzed the significance of STAS in other stages exclusively. Recently, Terada and colleagues found that STAS was an independent predictor of recurrence in stage III (N2) ADC [15]. In the current study, STAS was found to be associated with poor DFS and OS in stage III patients but not in stage III-IV cases. This observation indicates that the prognostic significance of STAS mainly exists in early-stage ADC cases, and pathological evaluation of STAS should be performed more cautiously for these tumors. In the analysis of single-stage ADC, STAS was associated with poor DFS in stage I, II, IA, IB, and IIA patients, but not OS. These results reveal more details on the significance of STAS with respect to recurrence. When STAS is observed in these lymph 
Table 4 Univariate survival analysis of DFS and OS in ADC

\begin{tabular}{|c|c|c|c|c|}
\hline \multirow[t]{2}{*}{ Parameters } & \multicolumn{2}{|l|}{ DFS } & \multicolumn{2}{|l|}{ OS } \\
\hline & Mean DFS (month) & $p$ & Mean OS (month) & $p$ \\
\hline \multicolumn{5}{|l|}{ Age } \\
\hline$\leq 65$ & 44.34 & 0.228 & 58.92 & 0.033 \\
\hline$>65$ & 49.46 & & 56.52 & \\
\hline \multicolumn{5}{|l|}{ Tumor size } \\
\hline$\leq 3 \mathrm{~cm}$ & 49.61 & 0.002 & 60.22 & 0.054 \\
\hline$>3 \mathrm{~cm}$ & 41.87 & & 55.70 & \\
\hline \multicolumn{5}{|c|}{ Pleural invasion } \\
\hline Absent & 51.14 & $<0.001$ & 60.15 & 0.002 \\
\hline Present & 41.18 & & 55.45 & \\
\hline \multicolumn{5}{|c|}{ Vascular invasion } \\
\hline Absent & 49.17 & 0.064 & 60.56 & 0.009 \\
\hline Present & 41.21 & & 50.79 & \\
\hline \multicolumn{5}{|c|}{ Lymphatic invasion } \\
\hline Absent & 52.00 & $<0.001$ & 59.75 & 0.001 \\
\hline Present & 41.40 & & 55.06 & \\
\hline \multicolumn{5}{|c|}{ Perineural invasion } \\
\hline Absent & 47.39 & 0.598 & 59.00 & 0.266 \\
\hline Present & 43.89 & & 52.78 & \\
\hline \multicolumn{5}{|c|}{ Pathological stage } \\
\hline Stage I-II & 49.93 & $<0.001$ & 61.47 & $<0.001$ \\
\hline Stage III-IV & 37.65 & & 47.59 & \\
\hline \multicolumn{5}{|c|}{ Presence of micropapillary } \\
\hline Absent & 48.77 & 0.120 & 58.81 & 0.655 \\
\hline Present & 41.98 & & 55.58 & \\
\hline \multicolumn{5}{|l|}{ STAS } \\
\hline Absent & 55.73 & $<0.001$ & 60.72 & 0.025 \\
\hline Present & 40.42 & & 56.79 & \\
\hline \multicolumn{5}{|c|}{ STAS (in Stage I-II) } \\
\hline Absent & 58.20 & $<0.001$ & 62.96 & 0.015 \\
\hline Present & 41.91 & & 59.57 & \\
\hline \multicolumn{5}{|c|}{ STAS (in Stage III-IV) } \\
\hline Absent & 30.75 & 0.736 & 35.30 & 0.332 \\
\hline Present & 36.88 & & 48.87 & \\
\hline
\end{tabular}

node-negative ADCs, close follow-up should be implemented. Further studies are needed to discuss whether these patients need post-operative adjuvant therapy.

Only a few studies have analyzed STAS in SQCC. In SQCC, the incidence of STAS was generally lower than that in ADC, which was from 19.1\% [16] to 40.3\% [17]. Positive STAS was observed to be associated with larger tumor size, lymphovascular invasion, tumor necrosis, high-grade tumor budding, larger nuclear diameter, higher mitotic counts, and higher $\mathrm{T}, \mathrm{N}$, and p-stages [16-18]. In survival analyses, STAS was also reported to be a significant predictive factor of DFS and OS [16-18], especially in stage I patients [16]. In the current study, STAS was associated with shorter OS, although this trend was not statistically significant, and no correlation was found between STAS and DFS. This could be because the simple size of the current study was smaller than that of previous reports.

The association between STAS and molecular characteristics has not been clearly explicated. Molecular characteristics were exclusively studied in ADC. STAS was frequently observed in tumors with $A L K$ and ROS1 rearrangements, $B R A F$ mutations, or wild-type HER2 $[6,7$, 19-21]. In the current study, 95.8\% (23/24) cases with $A L K$ rearrangements and all cases with ROS1 rearrangements demonstrated STAS, and this observation was similar to that of previous results. Three articles reported the association between STAS and KRAS mutations; one study concluded that STAS was frequently observed in tumors with KRAS mutations, whereas the other two reported no association [7, 19, 20]. Our results also concluded no association between STAS and KRAS mutations. However, as the KRAS mutation rate is quite low in Asian patients, more data are needed to clarify this issue. Regarding EGFR mutations, the reported results have varied among different studies. According to $\mathrm{Hu}$ and colleagues, STAS is frequently observed in tumors with EGFR mutations [7], whereas three other studies demonstrated that STAS was associated with wild-type EGFR [19-21]. In contrast, in some studies, no correlation was observed between STAS and EGFR [2224]. In the current study, STAS was observed to be associated with wild-type EGFR. One possible explanation for the different frequencies of STAS based on different driver gene alterations could be that STAS is more frequently observed in poorly differentiated tumors including those with a solid/micropapillary pattern [25], and $A L K$ or ROS1 rearrangements mainly exist in ADC with a predominant solid pattern $[1,26]$. In contrast, STAS is also associated with a non-lepidic pattern $[1,7$, $19,20]$, whereas EGFR mutations were more frequently detected in ADC with lepidic growth [25].

The association between STAS and the expression of immunohistochemical markers was barely understood and the correlation between STAS and EMT has been poorly discussed. In ADC, positive STAS was reported to be significantly associated with tumor stroma metastasis-associated protein 1 expression levels [8] but was not significantly correlated with programmed death ligand 1, thyroid transcription factor 1, napsin, or CK7 expression, as well as Ki67 activity [19, 22, 23]. In the present study, STAS was found to be associated with lower E-cadherin and higher vimentin and Ki67 expression. In SQCC, previous reports concluded that STAS is associated with an increased tendency for high vimentin 

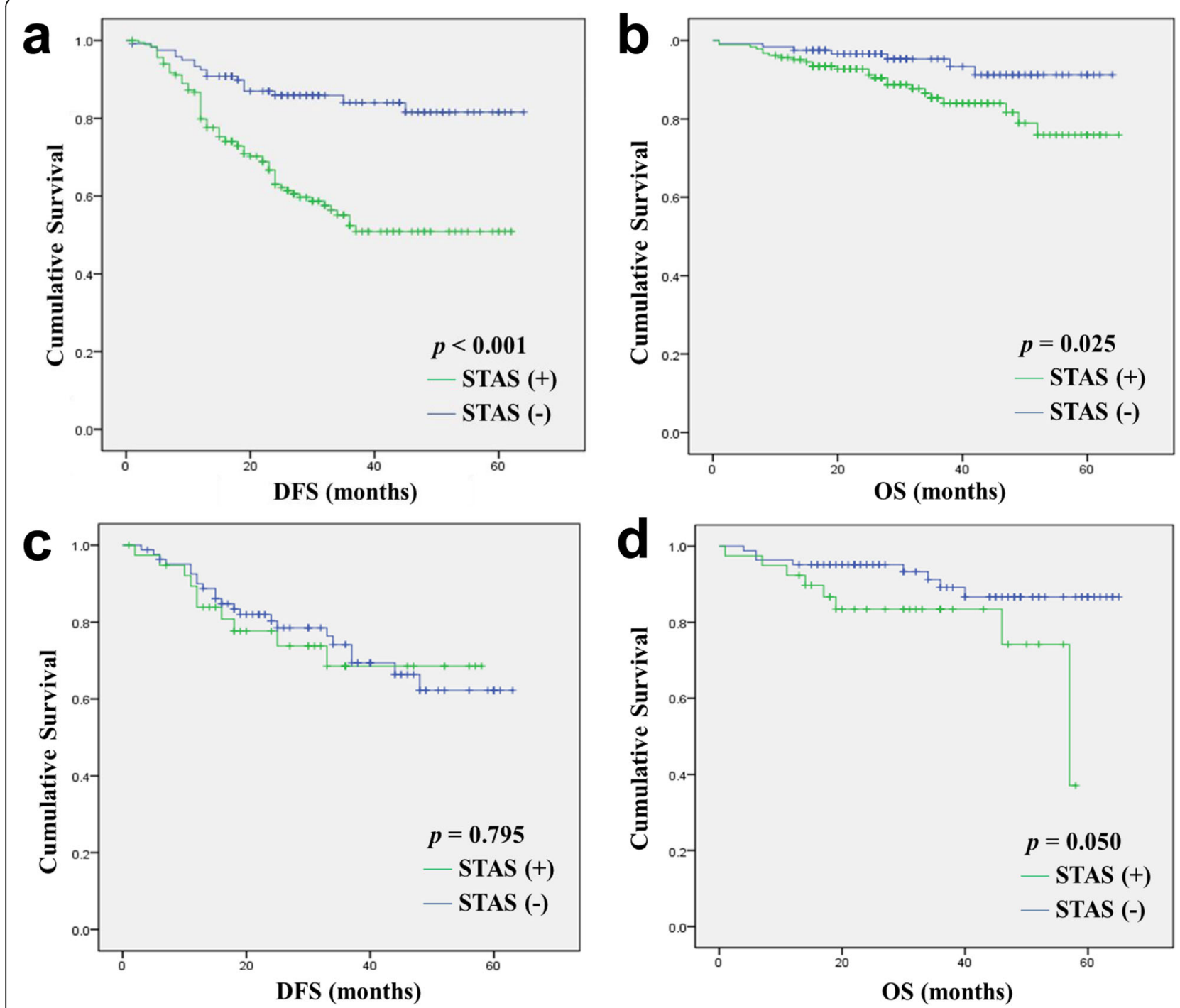

Fig. 2 Kaplan-Meier curves according to spread through air spaces (STAS) in all-stage lung adenocarcinoma (ADC) and squamous cell carcinoma (SQCC). a: Disease-free survival (DFS) in ADC ( $p<0.001)$; b: Overall survival (OS) in ADC $(p=0.025)$; : DFS in SQCC $(p=0.795)$; d: OS in $\operatorname{SQCC}(p=0.050)$

Table 5 Multivariate Cox analysis of DFS and OS in ADC

\begin{tabular}{|c|c|c|c|c|c|}
\hline \multirow[t]{2}{*}{ Parameters } & & \multicolumn{2}{|l|}{ DFS } & \multicolumn{2}{|l|}{ OS } \\
\hline & & $p$ & HR $(95 \% \mathrm{Cl})$ & $p$ & HR $(95 \% \mathrm{Cl})$ \\
\hline Age & $>65$ vs. $\leq 65$ & - & - & 0.009 & $2.637(1.275-5.455)$ \\
\hline Tumor size & $>3 \mathrm{~cm}$ vs. $\leq 3 \mathrm{~cm}$ & 0.137 & $1.383(0.902-2.119)$ & - & - \\
\hline Pleural invasion & Present vs. absent & 0.022 & $1.729(1.084-2.757)$ & 0.158 & $1.878(0.783-4.504)$ \\
\hline Vascular invasion & Present vs. absent & - & - & 0.459 & $1.341(0.617-2.916)$ \\
\hline Lymphatic invasion & Present vs. absent & 0.388 & $1.259(0.746-2.123)$ & 0.289 & $1.792(0.610-5.266)$ \\
\hline STAS & Present vs. absent & 0.002 & $2.460(1.398-4.327)$ & 0.719 & $1.187(0.466-3.026)$ \\
\hline Pathological stage & III, IV vs. I, II & 0.241 & $1.321(0.830-2.102)$ & 0.001 & 3.766 (1.710-8.296) \\
\hline
\end{tabular}



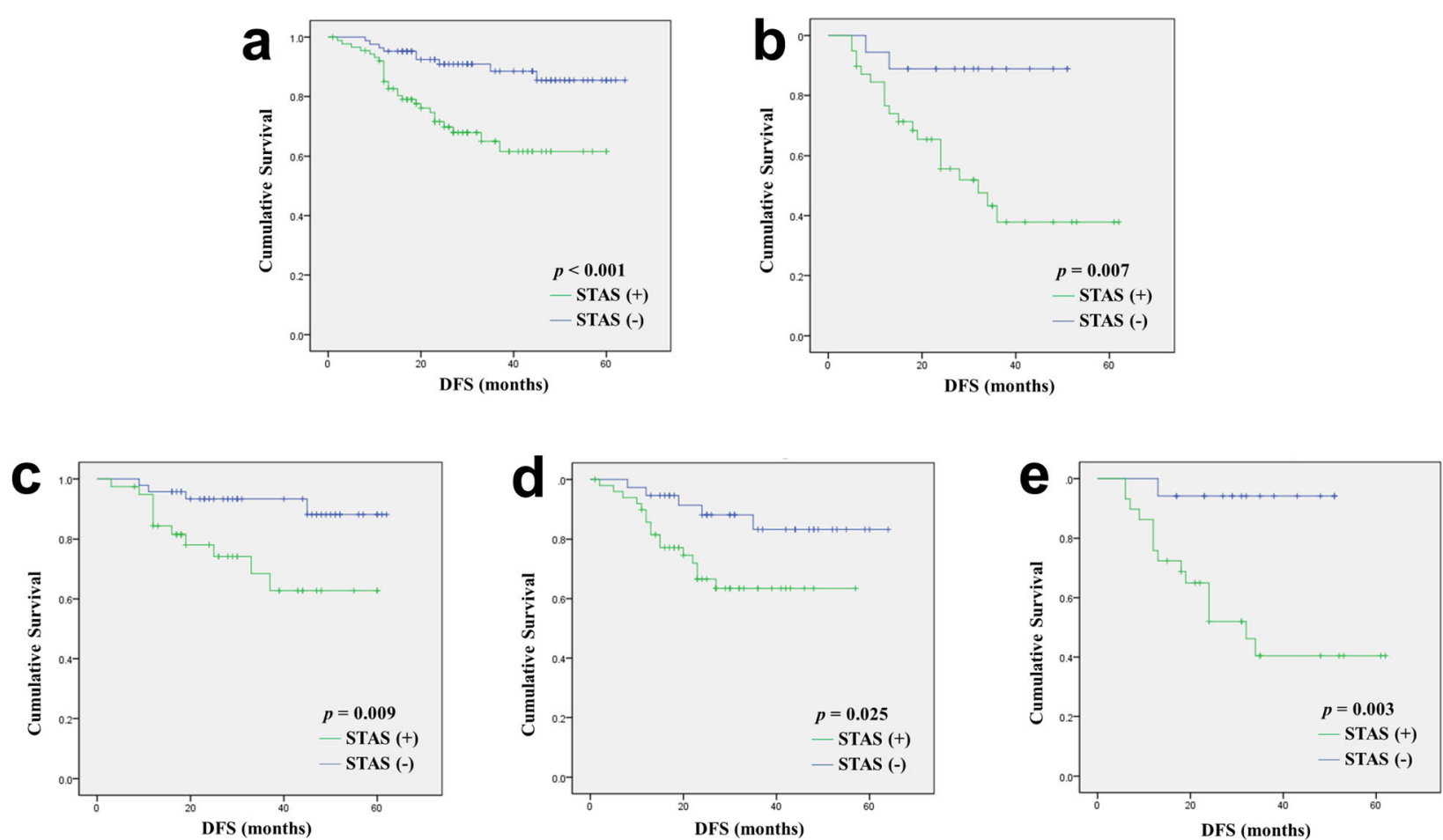

Fig. 3 Disease-free survival (DFS) according to spread through air spaces (STAS) in single-stage lung adenocarcinoma (ADC) cases. a: Stage I ( $p<$ $0.001) ; \mathbf{b}$ : stage II $(p=0.007)$; $\mathbf{c}$ : stage IA $(p=0.009) ; \mathbf{d}$ : stage IB $(p=0.025)$; e: stage IIA $(p=0.003)$

and Ki67 expression in comparison with levels in patients without STAS; however, the expression of p53 and E-cadherin was not associated with the status of STAS [16-18]. In the present study, STAS was found to be associated with lower E-cadherin and higher vimentin and survivin expression in the SQCC cohort. These results indicate that STAS might be more likely to be present in tumors exhibiting EMT features. EMT is a process by which epithelial cells transform into mesenchymal stem cells by losing their cell polarity and cell-to-cell adhesion and gaining migratory and invasive properties, and this process has been identified as an indicator of poor prognosis in non-small cell lung cancer [27]. Even though a relationship was found between the presence of STAS and EMT features, whether STAS cells underwent EMT remains unclear. According to Yagi and colleagues [28], the survival of STAS cells relies on blood vessel co-option, and these cells are E-cadherin-positive. This result, to some extent, challenged the opinion that STAS cells undergo EMT. In agreement with previous reports, the present results suggest that EMT might be a risk factor but not a mechanism for STAS, as tumors with EMT features were found to be more discohesive with fewer intercellular adhesions; this, it would be easier for the malignant cells to detach from the main tumor.

Our study had some limitations. On one hand, some early-stage patients in the present study received limited resection, and some patients with latestage tumors received adjuvant therapy. These conditions might have influenced the prognosis and could affect the results of survival analysis. On the other hand, the sample size involved in the present study was small, especially for SQCC, and the patients were from one single institution.

\section{Conclusions}

STAS is a risk factor for poor DFS and OS in lung ADC, and this significance mainly exists for early-stage (I-II) ADC cases. STAS is also associated with poor DFS for single-stage I, II, IA, IB, and IIA ADC patients. In SQCC, STAS-positive patients tended to have a poorer OS. Patients with STAS are more likely to harbor wildtype EGFR and rearranged ALK or ROS1. In both ADC and SQCC, STAS-positive tumors frequently showed EMT features. Our findings provide a better understanding of the implications of STAS with respect to clinicopathologic features, molecular characteristics, immunohistochemical expression, and prognosis in ADC and SQCC patients. 


\section{Supplementary information}

Supplementary information accompanies this paper at https://doi.org/10. 1186/s12885-020-07200-W.

Additional file 1: Supplementary Table 1. Primary antibodies used for immunohistochemistry

Additional file 2: Supplementary Table 2. Univariate survival analysis of DFS and OS in SQCC.

Additional file 3: Supplementary Table 3. Univariate survival analysis of DFS and OS in single stage ADC

Additional file 4: Supplementary Table 4. Multivariate Cox analysis of DFS in single stage ADC

\section{Abbreviations}

ADC: Adenocarcinoma; AJCC: American Joint Committee on Cancer; ALK: anaplastic lymphoma kinase; Cl: Confidence interval; DFS: Disease-free survival; EGFR: Epidermal growth factor receptor; EMT: Epithelialmesenchymal transition; HR: Hazard ratio; KRAS: Kirsten rat sarcoma vira oncogene homolog; MIA: Minimally invasive adenocarcinoma; OS: Overall survival; p-stage: Pathological stage; ROS1: ROS proto-oncogene 1, receptor tyrosine kinase; SQCC: Squamous cell carcinoma; STAS: Spread through air spaces; UICC: Union for International Cancer Control; WHO: World Health Organization

\section{Acknowledgements}

Not applicable.

\section{Authors' contributions}

MJ: investigation, formal analysis, writing - original draft; SLY: formal analysis; JQY: resources; YML: resources; HWG: project administration, writing - review \& editing, funding acquisition; PLS: conceptualization, writing - review \& editing, project administration, funding acquisition. All authors read and approved the final manuscript.

\section{Funding}

This work was supported by Science and Technology of Jilin Province, Jilin Province Key Laboratory (3D517K363429); The Role and Molecular Mechanism of EMT in the Resistance of ROS1-positive Lung Cancer (20180101014JC/3D518PS23429); Jilin Province Department of Finance Project (3D5197398429); Jilin Province Department of Finance Project (3D5197464429); and Youth Program of National Natural Science Foundation of China (3A4197642429). The research fund was used for data collection and immunohistochemical staining.

\section{Availability of data and materials}

The datasets used and/or analysed during the current study are available from the corresponding author on reasonable request.

\section{Ethics approval and consent to participate}

This study was approved by the ethics committee of The Second Hospital of Jilin University (2018-066). Written informed consent was also obtained from all patients.

\section{Consent for publication}

Not applicable.

\section{Competing interests}

The authors declare that they have no competing interests.

Received: 4 February 2020 Accepted: 21 July 2020

Published online: 29 July 2020

\section{References}

1. Kadota K, Nitadori J, Sima CS, Ujiie H, Rizk NP, Jones DR, Adusumilli PS, Travis WD. Tumor spread through air spaces is an important pattern of invasion and impacts the frequency and location of recurrences after limited resection for small stage I lung adenocarcinomas. J Thorac Oncol. 2015;10:806-14
2. Travis WD, Brambilla E, Burke AP, Marx A, Nicholson AG. WHO classification of Tumours of the lung, pleura, Thymus and heart. 4th ed. Lyon: IARC Press; 2015

3. Rami-Porta R, Bolejack V, Crowley J, Ball D, Kim J, Lyons G, Rice T, Suzuki K Thomas CF Jr, Travis WD, WU YL. The IASLC lung Cancer staging project: proposals for the revisions of the T descriptors in the forthcoming eighth edition of the TNM classification for lung Cancer. J Thorac Oncol. 2015;10: 990-1003.

4. Sun $P L$, Jin $Y$, Kim H, Seo AN, Jheon S, Lee $C T$, Chung JH. Survivin expression is an independent poor prognostic marker in lung adenocarcinoma but not in squamous cell carcinoma. Virchows Arch. 2013; 463:427-36

5. Kim H, Yoo SB, Choe JY, Paik JH, Xu X, Nitta H, Zhang W, Grogan TM, Lee $C T$, Jheon $\mathrm{S}$, Chung $\mathrm{JH}$. Detection of ALK gene rearrangement in non-small cell lung cancer: a comparison of fluorescence in situ hybridization and chromogenic in situ hybridization with correlation of ALK protein expression. J Thorac Oncol. 2011;6:1359-66.

6. Jin Y, Sun PL, Park SY, Kim H, Park E, Kim G, Cho S, Kim K, Lee CT, Chung JH. Frequent aerogenous spread with decreased $\mathrm{E}$-cadherin expression of ROS1-rearranged lung cancer predicts poor disease-free survival. Lung Cancer. 2015;89:343-9.

7. Hu SY, Hsieh MS, Hsu HH, Tsai TM, Chiang XH, Tsou KC, Liao HC, Lin MW, Chen JS. Correlation of tumor spread through air spaces and clinicopathological characteristics in surgically resected lung adenocarcinomas. Lung Cancer. 2018;126:189-93.

8. Liu Y, Chen D, Qiu X, Duan S, Zhang Y, Li F, Chen C, Zhou Y, Chen Y. Relationship between MTA1 and spread through air space and their joint influence on prognosis of patients with stage I-III lung adenocarcinoma. Lung Cancer. 2018;124:211-8.

9. $\quad$ Yang $L$, Yang $Y$, Ma P, Zheng B, Liu W, Zhang Z, Ding N, Liu L, Mao Y, Lv N. Spread through air spaces predicts a worse survival in patients with stage I adenocarcinomas $>2 \mathrm{~cm}$ after radical lobectomy. J Thorac Dis. 2018;10: 5308-17.

10. Bains S, Eguchi T, Warth A, Yeh YC, Nitadori II, Woo KM, Chou TY, Dienemann H, Muley T, Nakajima J, Shinozaki-Ushiku A, Wu YC, Lu S, Kadota K, Jones DR, Travis WD, Tan KS, Adusumilli PS. Procedure-specific risk prediction for recurrence in patients undergoing lobectomy or sublobar resection for small $(</=2 \mathrm{~cm})$ lung adenocarcinoma: an international cohort analysis. J Thorac Oncol. 2019;14:72-86.

11. Eguchi T, Kameda K, Lu S, Bott MJ, Tan KS, Montecalvo J, Chang JC, Rekhtman N, Jones DR, Travis WD, Adusumilli PS. Lobectomy is associated with better outcomes than sublobar resection in spread through air spaces (STAS)-positive T1 lung adenocarcinoma: a propensity score-matched analysis. J Thorac Oncol. 2019;14:87-98

12. Kadota K, Kushida Y, Kagawa S, Ishikawa R, Ibuki E, Inoue K, Go T, Yokomise $H$, Ishii T, Kadowaki N, Haba R. Limited resection is associated with a higher risk of Locoregional recurrence than lobectomy in stage I lung adenocarcinoma with tumor spread through air spaces. Am J Surg Pathol. 2019:43:1033-41.

13. Qiu X, Chen D, Liu Y, Duan S, Zhang F, Zhang Y, Li F, Chen C, Chen Y. Relationship between stromal cells and tumor spread through air spaces in lung adenocarcinoma. Thorac Cancer. 2019;10:256-67.

14. Ren Y, Xie H, Dai C, She Y, Su H, Xie D, Zheng H, Zhang L, Jiang G, Wu C, Chen C. Prognostic impact of tumor spread through air spaces in sublobar resection for 1A lung adenocarcinoma patients. Ann Surg Oncol. 2019;26: 1901-8.

15. Terada Y, Takahashi T, Morita S, Kashiwabara K, Nagayama K, Nitadori Jl, Anraku M, Sato M, Shinozaki-Ushiku A, Nakajima J. Spread through air spaces is an independent predictor of recurrence in stage III (N2) lung adenocarcinoma. Interact Cardiovasc Thorac Surg. 2019;29:442-8.

16. Yanagawa N, Shiono S, Endo M, Ogata SY. Tumor spread through air spaces is a useful predictor of recurrence and prognosis in stage I lung squamous cell carcinoma, but not in stage II and III. Lung Cancer. 2018;120:14-21.

17. Kadota K, Kushida $Y$, Katsuki N, Ishikawa R, Ibuki E, Motoyama M, Nii K, Yokomise H, Bandoh S, Haba R. Tumor spread through air spaces is an independent predictor of recurrence-free survival in patients with resected lung squamous cell carcinoma. Am J Surg Pathol. 2017;41:1077-86.

18. Lu S, Tan KS, Kadota K, Eguchi T, Bains S, Rekhtman N, Adusumilli PS, Travis WD. Spread through air spaces (STAS) is an independent predictor of recurrence and lung Cancer-specific death in squamous cell carcinoma. J Thorac Oncol. 2017:12:223-34. 
19. Warth A, Muley T, Kossakowski CA, Goeppert B, Schirmacher P, Dienemann $\mathrm{H}$, Weichert W. Prognostic impact of intra-alveolar tumor spread in pulmonary adenocarcinoma. Am J Surg Pathol. 2015;39:793-801.

20. Lee JS, Kim EK, Kim M, Shim HS. Genetic and clinicopathologic characteristics of lung adenocarcinoma with tumor spread through air spaces. Lung Cancer. 2018;123:121-6.

21. Kim SK, Kim TJ. Lung adenocarcinoma: CT features associated with spread through air spaces. Radiology. 2018;289:831-40.

22. Toyokawa G, Yamada Y, Tagawa T, Kinoshita F, Kozuma Y, Matsubara T, Haratake N, Takamori S, Akamine T, Hirai F, Oda Y, Maehara Y. Significance of spread through air spaces in resected lung adenocarcinomas with lymph node metastasis. Clin Lung Cancer. 2018;19:395-400 e1.

23. Toyokawa G, Yamada Y, Tagawa T, Kozuma Y, Matsubara T, Haratake N, Takamori S, Akamine T, Oda Y, Maehara Y. Significance of spread through air spaces in resected pathological stage I lung adenocarcinoma. Ann Thorac Surg. 2018;105:1655-63.

24. Toyokawa G, Yamada Y, Tagawa T, Oda Y. Significance of spread through air spaces in early-stage lung adenocarcinomas undergoing limited resection. Thorac Cancer. 2018;9:1255-61.

25. Kim J, Jang SJ, Choi CM, Ro JY. Correlation of histologic subtypes and molecular alterations in pulmonary adenocarcinoma: therapeutic and prognostic implications. Adv Anat Pathol. 2016;23:330-8.

26. Masai K, Sakurai H, Sukeda A, Suzuki S, Asakura K, Nakagawa K, Asamura H, Watanabe Sl, Motoi N, Hiraoka N. Prognostic impact of margin distance and tumor spread through air spaces in limited resection for primary lung Cancer. J Thorac Oncol. 2017:12:1788-97.

27. Tsoukalas N, Aravantinou-Fatorou E, Tolia M, Giaginis C, Galanopoulos M, Kiakou M, Kostakis ID, Dana E, Vamvakaris I, Korogiannos A, Tsiambas E, Salemis N, Kyrgias G, Karameris A, Theocharis S. Epithelial-Mesenchymal transition in non small-cell lung Cancer. Anticancer Res. 2017:37:1773-8.

28. Yagi Y, Aly R, Tabata K, Rekhtman N, Eguchi T, Montecalvo J, Manova K, Adusumilli P, Hameed M, Travis W. OA03.07 Three-Dimensional Immunofluorescence Analysis of Dynamic Vessel Co-Option of Spread Through Air Spaces (STAS) in Lung Cancer. J Thorac Oncol. 2018;13:S327.

\section{Publisher's Note}

Springer Nature remains neutral with regard to jurisdictional claims in published maps and institutional affiliations.

Ready to submit your research? Choose BMC and benefit from:

- fast, convenient online submission

- thorough peer review by experienced researchers in your field

- rapid publication on acceptance

- support for research data, including large and complex data types

- gold Open Access which fosters wider collaboration and increased citations

- maximum visibility for your research: over $100 \mathrm{M}$ website views per year

At $\mathrm{BMC}$, research is always in progress.

Learn more biomedcentral.com/submissions 